\title{
Association between Smoking and Academic Performance among Under-Graduate Students of Pakistan, A Cross-Sectional Study
}

\author{
Sana Ullah ( $\nabla$ sanak3@gmail.com ) \\ Health Services academy Islamabad, Pakistan \\ Siham Sikander \\ Health Services academy Islamabad, Pakistan. \\ Mudassar Mushtaq Jawad Abbasi \\ Health Services academy Islamabad, Pakistan \\ Syed Aftab Rahim \\ Health Services academy Islamabad, Pakistan \\ Babar Hayat \\ Health Services academy Islamabad, Pakistan \\ Zaeem UI Haq \\ health Services Academy Islamabad, Pakistan \\ Iftikhar Ahmad \\ Al-Shifa School of Public Health, Rawalpindi, Pakistan
}

Research article

Keywords: GPA, Smoking, Undergraduate, Students, Youth, Academic performance.

Posted Date: August 14th, 2019

DOl: https://doi.org/10.21203/rs.2.12718/v1

License: (9) (1) This work is licensed under a Creative Commons Attribution 4.0 International License. Read Full License 


\section{Abstract}

Background Prevalence of smoking is on the rise and its harmful effects on every organ of body are well known. Smoking is a growing concern due to adverse effects on health, its association with academic performance is not well studied. Objectives This study aims to assess the prevalence of smoking among undergraduate students of age 18-24 years in a public sector university of Islamabad, association between smoking and academic performance and also to assess the reasons of smoking initiation among undergraduate students. Methods The study included 500 undergraduate students. A self-report structured questionnaire was used to assess smoking, dietary habits, physical activity, parent's smoking, friend's smoking, time spent on mobile and TV and academic performance for collection of data. Logistic regression was used for association between smoking and academic performance. Results Results of study show that $112 / 500$ (22.4\%) students were smokers among them 93/112 (34.6\%) were males and 19/112 (8.2\%) were females. The mean age of study participants was 21.50 years (SD: 1.72. Prevalence of smoking was higher in students belonging to rural areas $23.5 \%$ to that of urban areas $21.9 \%$. Three major reasons of smoking initiation; $25 \%$ students stated peers and friends, $21 \%$ stated easy availability while $14 \%$ said it was fun and enjoyment they started smoking. High academic performance was found to be inversely proportional to student's smoking; at p-value 0.000 smokers had $2.5(1.77,3.74)$ odds of lower academic performance, boys having $2.17(1.56,3.03)$ odds of lower academic performance in last semester exams. Conclusion Findings highlighted extensive cigarette smoking among undergraduate students of Islamabad. Smoking is significantly and negatively associated with academic performance.

\section{Introduction}

According to world health organization any substance which changes mental or physical functions are called psycho active substances. The Diagnostic and Statistical Manual of Mental Disorders (DSM-V) defines substance abuse as self-administration of any drug, which deviates from approved social or medical patterns (1). Regardless of negative impacts substance is always used by youth, use of psycho active substance like tobacco products, alcohol beverages and marijuana have become major public health issues (2). Substance use in students is associated with many different factors like peer pressure, age, sex, personal pleasure, family substance abuse and poor academic achievement (3-6). "Substance use in young people (aged 10-24 years) might disrupt key periods of transition that occur as the adolescent brain undergoes cognitive and emotional development, and key psychosocial transitions are made". Adolescence is the vulnerable phase, since this is the time when substance use initiated, which have a negative impact on their (adolescents) academic performance as well (7). Substance abuse is becoming a a major concern among students, the use of substance including smoking, is known for its significant association with mental distress and consequently this mental distress can affect the students' academic performance negatively (8). Smoking depends on education, those who are more educated having less chances of being smokers and the study also showed that prevalence of smoking decreased with increase in educational level (9). Smoking is negatively associated with academic performance, while smoking has consistently stronger effect on academic performance than cannabis. Students with poorer grades had greater tendency to smoking than those who had good grades (10). Smoking predicated lower educational performance and lower school performance of adolescents predicated higher likelihood of their engagement in smoking behavior (11). Ten (10) percent students among 
excellent grades achievers reported weekly smoking, while the percentage of weekly smoking was 50 among students with poor grades (12). A Norwegian study on adolescents to find association between lifestyle habits and academic performance shows that smoking is inversely proportional to academic achievement (13). Academic performance and smoking initiation in adolescents, shows 3 trajectories of academic performance which are; among persistently higher achievers $7.1 \%$ students were smokers, $15.1 \%$ were smokers among average academic achievers while $49.1 \%$ were among unstable and low achievers (14). Cigarette smoking is one of the strongest predicator of poor academic performance among students (15-18). Some students use substance for good academic performance (19). There are approximately 23.6 million (age15-45) tobacco users in Pakistan. Pakistan's population comprises 63\% of youth; 58.5 million are 20-24 years of age (20). According to a Karachi based study the prevalence of smoking among university students was $23 \%$ in Pakistan (6). Smoking is on the rise among younger population (21) and its association with serious health issues has been known since decades $(22,23)$,one neglected aspect of tobacco use is its association with poor academic performance among Pakistani students. Smoking not only represents an impact on economics but also depriving country of a healthy work force this increasing disease burden on the health sector which already stressed with double burden of disease along with impacting academic performances of youngsters by disrupting various biological and psychological phenomenon. To our knowledge no prior studies examined association between smoking and academic performance among Pakistani students.

\section{Methods}

\section{Data and study design}

Cross-sectional study was conducted in a public sector university of Islamabad. Sample size was calculated with a $15 \%$ prevalence of smoking among undergraduate students with $80 \%$ power and $95 \%$ confidence interval, by considering design effect the final sample size was 500 . Study participants were selected a) stratified based on departments b) sample allocation based on departments' strength c) sample recruited randomly in every department. Data was collected from undergraduate student of 18-24 years of age. First

semester students were excluded from the study because they were not yet appeared in university exams and had no results.

\section{Variables}

The variables studied in study were academic performance which was dependent variable and student's smoking was main independent variable. Some of covariates were identified on weekly basis i.e. intake of breakfast in days last week, physical activity for at least 60 minutes in last 7 days, fruits and vegetables consumption frequency in last 7 days, students' mobile usage in hours per day and number of cigarettes smoked per day in last week.

Others covariates include demographics, age, gender, socioeconomic status, the region to which students belonged, residential settings, parent's and peer's smoking and father's and mother's education respectively.

\section{Potential confounders}


We identified potential confounders from certain studies based on research suggestions that they might be associated with academic performance e.g. physical activity, time spent on mobile and TV, breakfast and fruits and vegetables consumption.

\section{Instrument}

The questionnaire was developed based on literature review, which consisted of 30 questions, most of the questions were pre-coded and closed-ended responses. It was consisted of four sections: (i) sociodemographic (ii) physical activity (iii) dietary patterns and (iv) smoking status of students. Smoker is defined in this study as; an adult who smoked 100 cigarettes in his or her lifetime, and who currently smoked a cigarette per day. The questionnaire was developed and piloted in English on another university's students, proper and significant measures were made before being utilized for genuine data collection.

The data were collected in auditorium or classrooms, with at least in presence of one member of project to answer the study participants' questions and queries. Informed consent was taken from all the participants and was assured confidentiality and anonymity. The instrument was self-administered and the students were given both written and oral instructions on how to attempt the questions, and approximately 30 minutes to answer the questionnaire.

\section{Data analysis}

Based on the nature, data was weighted by percentage of gender, family income status; the region students belong to, residential settings (urban and rural) and type of student (boarder or day scholar). The first association was examined through bivariate analysis between smoking and academic performance, breakfast frequency, mobile usage per day, type of student, gender and the region. Logistic regression was used to find out the influence of each variable on academic performance and then controlled all those variables which were affecting academic performance. SPSS 20.0 was used for all statistical analysis.

\section{Ethical consideration}

The Internal review Board (IRB) of Health Services Academy approved the research protocol, and written consent was obtained from all study participants before their participation in the study. Data was collected during university time and also written permission was taken from concerned authorities of university.

\section{Results}

Data of total 500 undergraduate students was analyzed, among them 269 (53.8\%) were males and 231 $(46.2 \%)$ were females. The mean age of study participants was 21.50 years (SD: 1.72$)$. Table 1 shows the socio demographics of participants by gender.

\section{Table 1 Socio-demographic Characteristics of students}




\begin{tabular}{|l|l|l|l|}
\hline \multirow{2}{*}{ Characteristics } & \multicolumn{3}{|c|}{ Gender } \\
\cline { 2 - 4 } Residential settings Urban & Male, $\mathbf{n}(\%)$ & Female, $\mathbf{n}(\%)$ & Total, $\mathbf{n}(\%)$ \\
\hline & $157(58.4)$ & $181(78.4)$ & $338(67.6)$ \\
& $112(41.6)$ & $50(21.6)$ & $162(32.4)$ \\
\hline Region & $24(8.9)$ & $11(4.8)$ & $35(7.0)$ \\
Sindh & $121(45.0)$ & $140(60.6)$ & $261(52.2)$ \\
Kunjab & $77(28.6)$ & $33(14.3)$ & $110(22.0)$ \\
Balochistan Islamabad & $20(7.4)$ & $2(0.9)$ & $22(4.4)$ \\
Gilgit Baltistan & $6(2.2)$ & $19(8.2)$ & $25(5.0)$ \\
Azad Kashmir & $14(5.2)$ & $6(2.6)$ & $20(4.0)$ \\
& $7(2.5)$ & $20(8.7)$ & $27(5.4)$ \\
\hline Family Income Status & & & \\
Low income family & $18(6.7)$ & $5(2.2)$ & $23(4.6)$ \\
Middle income family & $226(84.0)$ & $210(90.9)$ & $436(87.2)$ \\
High income family & $25(9.3)$ & $16(6.9)$ & $41(8.2)$ \\
\hline Father's Education & $18(6.7)$ & $6(2.6)$ & $24(4.8)$ \\
Illiterate & $20(7.4)$ & $11(4.8)$ & $31(6.2)$ \\
Primary & $73(27.1)$ & $48(20.8)$ & $121(24.2)$ \\
Matric & $104(38.7)$ & $93(40.3)$ & $197(39.4)$ \\
Graduate & $54(20.1)$ & $73(31.6)$ & $127(25.4)$ \\
Post graduate or higher & & & \\
\hline Mother's Education & $85(31.6)$ & $24(10.4)$ & $109(21.8)$ \\
Illiterate & $56(20.8)$ & $30(13.0)$ & $86(17.2)$ \\
Primary & $55(20.4)$ & $59(25.5)$ & $114(22.8)$ \\
Matric & $60(22.3)$ & $83(35.9)$ & $143(28.6)$ \\
Graduate & $13(4.8)$ & $35(15.2)$ & $48(9.6)$ \\
Post graduate or higher & & &
\end{tabular}

With regard to the background residence $67.7 \%$ of students were from urban areas, and $32.4 \%$ were from rural areas of the country (Table 1 ). Similarly about $66.6 \%$ were day scholars and $33.4 \%$ were boarder scholars. Students from low income families were $4.6 \%$ while females from this economic class were just $5(2.2 \%)$ of all female study participants. Islamabad, Punjab and Azad Kashmir were exception among regions from where female students' strength was higher to that of male students. Parents' education revealed that $4.8 \%$ of fathers and $21.8 \%$ of mothers were reported illiterate, with only $9.6 \%$ mothers and $25.4 \%$ fathers were postgraduates or highly educated, higher education of parents especially of mothers increases chances of girls' higher education.

Table 2 displays prevalence of smoking by gender. Smoking was reported by $22.4 \%$ students, there was significant difference between both males and females smoking patterns, a larger number of males $34.6 \%$ reported smoking than those of $8.2 \%$ females, the prevalence of smoking was high $23.5 \%$ in rural students while $21.9 \%$ in urban students. Smoking prevalence in was $36.6 \%, 26.1 \%$ and $20.9 \%$ in students belonged to high, lower and middle income families respectively. 


\begin{tabular}{|c|c|c|}
\hline \multirow[t]{2}{*}{ Variable } & \multicolumn{2}{|r|}{ Smoking } \\
\hline & Yes n (\%) & No $n(\%)$ \\
\hline Students & $112(22.4)$ & $388(77.6)$ \\
\hline \multicolumn{3}{|l|}{ Gender } \\
\hline Male & $93(34.6)$ & $176(65.4)$ \\
\hline Female & $19(8.2)$ & $212(91.8)$ \\
\hline \multicolumn{3}{|l|}{ Residential settings } \\
\hline Urban & $74(21.9)$ & $264(78.1)$ \\
\hline Rural & 38 (23.5) & 124 (76.5) \\
\hline \multicolumn{3}{|l|}{\begin{tabular}{|l|} 
Family income status \\
\end{tabular}} \\
\hline Low income & $6(26.1)$ & $17(73.9)$ \\
\hline Middle income & $91(20.9)$ & $345(79.1)$ \\
\hline High income & $15(36.6)$ & $26(63.4)$ \\
\hline \multicolumn{3}{|l|}{ Region } \\
\hline Sindh & $11(31.4)$ & $24(68.6)$ \\
\hline Punjab & $47(18.0)$ & $214(82.0)$ \\
\hline Khyber Pakhtunkhwa & $30(27.3)$ & $80(72.7)$ \\
\hline Balochistan & 9 (40.9) & $13(51.1)$ \\
\hline Gilgit Baltistan & $7(35.0)$ & $13(65.0)$ \\
\hline Azad Kashmir & $4(14.8)$ & $23(85.2)$ \\
\hline Islamabad & $4(16.0)$ & $21(84.0)$ \\
\hline \multicolumn{3}{|l|}{ Student type } \\
\hline Day Scholar & $60(18.0)$ & $273(82)$ \\
\hline Boarder Scholar & $52(31.1)$ & 115 (68.9) \\
\hline \multicolumn{3}{|c|}{ Reasons of Smoking initiation/ Determinants } \\
\hline Variables & \multicolumn{2}{|l|}{ n (\%) } \\
\hline Peers & \multicolumn{2}{|l|}{$28(25.2)$} \\
\hline Easy Availability & \multicolumn{2}{|l|}{$23(20.7)$} \\
\hline Fun \& Enjoyment & \multicolumn{2}{|l|}{15 (13.5) } \\
\hline Movies & \multicolumn{2}{|l|}{$13(11.7)$} \\
\hline Failure in Love & \multicolumn{2}{|l|}{$11(9.9)$} \\
\hline Advertisement & \multicolumn{2}{|l|}{$8(7.2)$} \\
\hline Curiosity & \multicolumn{2}{|l|}{$8(7.2)$} \\
\hline Parents & \multicolumn{2}{|l|}{$5(4.5)$} \\
\hline \multicolumn{3}{|c|}{ Cigarettes Consumed per Day } \\
\hline Variables & \multicolumn{2}{|l|}{$\mathrm{n}(\%)$} \\
\hline 1 cigarette & \multicolumn{2}{|l|}{$30(26.8)$} \\
\hline 2-5 cigarettes & \multicolumn{2}{|l|}{$36(32.1)$} \\
\hline 6-10 cigarettes & \multicolumn{2}{|l|}{$22(19.6)$} \\
\hline $11-20$ cigarettes & \multicolumn{2}{|l|}{$18(16.1)$} \\
\hline More than 20 cigarettes & \multicolumn{2}{|l|}{$6(5.4)$} \\
\hline
\end{tabular}

Smokers among boarder scholars were $31.1 \%$ while $18 \%$ in day scholars. Smoking prevalence among students from different regions was $40.9 \%$ high among Balochistan, 35\% in Gilgit Baltistan, $31.4 \%$ in Sindh, 27.3\% in Khyber Pakhtunkhwa, 18\% in Punjab, 16\% in Islamabad, and 14.85 in Azad Kashmir. 
Association between academic performance and different variables first assessed with chi-square test and then logistic regression applied.

Significantly associated variables to academic performance were smoking, table 3 shows increased odds ratio of high academic performance in non-smoker students (OR= 2.57, 95\% Cl: 1.77, 3.74), analysis showed increased odds of high academic performance in females $(\mathrm{OR}=2.17,95 \% \mathrm{Cl}: 1.56,3.03)$, students having an intimate smoker friend also had increased odds of lower academic performance $(\mathrm{OR}=2.00,95 \% \mathrm{Cl}: 1.14$, 2.79) and student whose parents were smokers also had higher odds of lower academic performance (OR= 1.61, 95\% Cl: 1.11, 2.31).

\section{Table 3: Association of academic performance with selected variables}

\begin{tabular}{|l|l|l|}
\hline Variable & P-value & OR 95\% CI \\
& & \\
\hline Smoking & 0.000 & $2.57(1.77,3.74)$ \\
Gender & 0.000 & $2.17(1.56,3.03)$ \\
Friends' Smoke & 0.000 & $2.00(1.14,2.79)$ \\
Parents' Smoke & 0.011 & $1.61(1.11,2.31)$ \\
Residence & 0.405 & $0.86(0.62,1.20)$ \\
Type of Student & 0.355 & $0.87(0.61,1.18)$ \\
Life Event & 0.468 & $1.12(0.82,1.53)$ \\
\hline
\end{tabular}

Academic performance was not significantly associated with residence (urban, rural), type of student (boarder, day scholars) and having any life event (illness, accident, close relative death) during examinations days or two weeks ago.

\section{Reasons of Smoking}

Table 2 shows the reasons behind smoking initiation among students were; 28 (25.2\%) started smoking because of peers, $13(11.7 \%)$ stated that it were movies which gave them idea of cigarette smoking, 5 (4.5\%) started smoking looking at their parents while smoking, 8 (7.2\%) stated advertisement was the reason they started smoking, 23 (20.7\%) said they started smoking due to easy availability,15 (13.50\%) stated fun and enjoyment the reason they started smoking, 8 (7.2\%)stated curiosity the reason of their smoking and 11 $(9.90 \%)$ stated failure in love the reason of smoking initiation.

\section{Frequency of cigarettes smoked}

Table 2 shows the pattern of cigarettes smoked by students, 30 (26.8\%) reported 1 cigarette a day, 36 (32.1\%) reported 2-5 cigarettes, those who consumed 4-6 cigarettes per day were 22 (19.6\%), while 11-20 cigarettes consumers were $18(16.1 \%)$ and $6(5.4 \%)$ reported 20 or more cigarettes consumption per day. 
Figure 1 shows that among smokers 5 (4.5\%) started smoking when they were around 8 years or younger, 6 (5.4\%) participants started smoking when they were 9-10 years old, 7 (6.3\%) respondents started smoking when they were 11-12 years old, 12 (10.7\%) started smoking at age 13-14 years, 22 (19.6\%) started smoking when they were 15-16 years old and 60 (53.6\%) were those who started smoking at age of 17 or older.

\section{Discussion}

\section{Prevalence of Smoking}

The overall prevalence of cigarette smoking in this survey was $22.4 \%, 34.6 \%$ among males and $8.2 \%$ among females other studies from Pakistan also have same results of smoking prevalence among college students it was $24 \%$ (24) another study conducted in Karachi showed overall prevalence $23 \%$, 31\% male and $6 \%$ female were smoker (6) among university students. However an earlier study of medical students, conducted in Karachi showed overall prevalence $14.4 \%, 22.2 \%$ males and 3.8\% females (25). While another Pakistani study showed $21.6 \%$ as average national prevalence of cigarette smoking (26). Prevalence of smoking among adults in United States was 19\% (27), while 19.3\% in Iranian high school students, where $20.2 \%$ boys and $8.8 \%$ girls were smokers (28). Prevalence among Nepalese junior collegiate was $9.4 \%$, prevalence among boys and girls students was $20.5 \%$ and $2.9 \%$ respectively (29). The age group of Iranian and Nepali students was different, which indicate low prevalence of smoking. Among Ethiopian medical students the prevalence was $29.5 \%$ (30) this prevalence was remarkable high.

The prevalence of smoking was higher among students belonged to rural areas compared to the students belonged to urban areas in this study. A study on impact of socio-demographic factors by Jamal Abdul Nasir and colleagues showed $51.5 \%$ of rural study respondents and $48.5 \%$ urban were smokers (31), a study of northern areas of Pakistan also showed higher prevalence of smoking than that of urban areas (32), a study by Ali Yawar Alam and colleagues also showed high prevalence of smoking among rural citizens (33). It is an established fact that smoking prevalence very much depends on geographical area and location of residence (34). Frequency of cigarettes smoked was lower reported, $30 \%$ of smokers reported that they smoke 1 cigarette per day which is much less than what is reported in Pakistani study and global adult tobacco survey $(6,8,31,35,36)$ but somehow similar to that of Shafquat Rozi and colleagues' study on college students in Karachi (24) and the Chinese study on inner Mongolian medical students (37).

\section{Determinants}

Twenty five percent (25\%) students reported that since their friends smoked they took up smoking as part of their social interaction, $21 \%$ of smokers said that it was easy availability of cigarettes in market which encourage them to smoke, $12 \%$ respondents stated movies a reason of taking up cigarette smoking, only $4.5 \%$ stated parents and family a reason to start smoking, this value is much less than other studies, $7 \%$ students were stating advertisements a reason to smoke and 7\% stated curiosity, these reasons were similar to previous studies with a slight difference in percentages $(4,5,29,36-38)$.

Association between Smoking and Academic performance 
Smoking was negatively associated with academic performance, the odds of being a smoker and having lower GPA was 2.5. These findings were exactly same to that of a Korean and Mississippian studies (18,39) the finding was consistent with studies done in Finland and Ethiopia $(8,10-12)$ but higher than that of Norwegian study (13) the Norwegian study was conducted on adolescents 15-17 years old, they have limited access to cigarettes which may limit their frequency of cigarette smoking, while in present study respondents were youth 18-24 years old.

\section{Conclusions}

Findings of this study highlight high smoking prevalence among undergraduate students. The high prevalence of smoking is of high concern and its effect on academic performance is particularly of more concern. Smoking was significantly and negatively associated with academic performance. Prevalence of low academic performance was high in smokers, males, students having smoker parents and or friends. The variables investigated in this study explained that smoking is a strong predictor of poor academic performance among university students. Despite the shortcomings this study will contribute to scientific literature and also help inform public policies and practices. Findings of this study are meaningful to the discussion about the negative effects of smoking and academic performance. These findings also identify the important target population for intervention.

\section{Limitations}

This study has some limitations, first there may be a selection bias the sample was not nationally representative. Second only one Public Sector University was selected; other private and public sector universities were not included in this study. Third only graduate students were part of the study but Masters and PhD students were not included in this study. Fourth Self-reporting may affect the quality of study data, even though appropriate measures were taken during data collection to assess actual performance. To minimize this problem, an appropriate explanation was given to the participants on the importance of reporting their actual academic performance. Fifth the study was a cross-sectional which reduces the ability to make direct causal inferences from data.

\section{Recommendations}

University should take strict measure to make hostels and campus smoke free, because smoking prevalence among boarder scholars is alarming and worrisome.

This research holds strong significance for researchers and public health practitioners in the field of health promotion and education, which is more specific to undergraduate students of a multicultural and multi ethnic country. This would contribute to some newer and effective solutions to improve academic performance and smoking cessation.

\section{Declarations}

Ethics Approval and Consent to Participate: 
Ethical approval was taken from Internal Review Board (IRB) of Health Services Academy Islamabad. Since all the study participants were literate informed consent was taken in written from all the participants and was assured confidentiality and anonymity.

Availability of data and materials:

The datasets used in current study are not available publically, but on reasonable request available from corresponding author.

Competing Interest:

The authors declared no competing interest.

Funding:

None

Consent of publication:

Not applicable.

Authors' Contributions:

Sana Ullah and Siham Sikander conceptualized the study, participated in its design, coordination, questionnaire development and draft writing. Mudassar Mushtaq Jawad Abbasi performed statistical analysis. Syed Aftab Rahim, Babar Hayat and Iftikhar Ahmad helped in data collection. The manuscript was revised for intellectual content by Sana ullah, Siham Sikander, Zaeem UI Haq and Mudassar Mushtaq Jawad Abbasi, they also provided expert advice on analysis and variable interpretation. All authors read and approved submission for final manuscript.

\section{References}

1. WHO | Abuse (drug, alcohol, chemical, substance or psychoactive substance). WHO [Internet]. 2010 [cited 2018 Dec 28]; Available from: https://www.who.int/substance_abuse/terminology/abuse/en/

2. Deressa W, Azazh A. Substance use and its predictors among undergraduate medical students of Addis Ababa University in Ethiopiaruc [Internet]. 2011 [cited 2018 Aug 20]. Available from: http://www.biomedcentral.com/1471-2458/11/660

3. Tehrani MA, Moghadam FM, Sh K. Smoking Frequency and some Related Factors among High School Students of Kashan City, Iran [Internet]. Vol. 2, Int Arch Health Sci Summer. 2015 [cited 2018 Aug 16]. Available from: http://www.ncbi.nlm.nih.gov/mesh/68013334];

4. Xu X, Liu D, Sharma M, Zhao Y. Prevalence and Determinants of Current Smoking and Intention to Smoke among Secondary School Students: A Cross-Sectional Survey among Han and Tujia Nationalities in China. J Environ Res Public Heal [Internet]. 2017 [cited 2018 Aug 16];14. Available from: www.mdpi.com/journal/ijerph 
5. Mckelvey K, Attonito Phd J, Madhivanan P, Phd QY, Phd FM, Maziak Phd W. Determinants of Cigarette Smoking Initiation in Jordanian Schoolchildren: Longitudinal Analysis. Nicotine Tob Res [Internet]. 2015 [cited 2018 Aug 16];552-8. Available from:

https://www.ncbi.nlm.nih.gov/pmc/articles/PMC4432393/pdf/ntu165.pdf

6. Rashid Ahmed1,3, Rizwan-ur-Rashid2, Paul W. McDonald1,4,5 SWA. prevalence of cigarette smoking among young adults in Pakistan. jpma [Internet]. [cited 2018 Apr 23]; Available from: http://jpma.org.pk/PdfDownload/1538.pdf

7. Stockings E, Hall WD, Lynskey M, Morley KI, Reavley N, Strang J, et al. Prevention, early intervention, harm reduction, and treatment of substance use in young people. The Lancet Psychiatry [Internet]. 2016;3(3):280-96. Available from: http://dx.doi.org/10.1016/S2215-0366(16)00002-X

8. Mekonen T, Fekadu W, Mekonnen TC, Workie SB. Substance Use as a Strong Predictor of Poor Academic Achievement among University Students. [cited 2018 Apr 23]; Available from: https://www.ncbi.nlm.nih.gov/pmc/articles/PMC5478866/pdf/PSYCHIATRY2017-7517450.pdf

9. Maralani V. Understanding the links between education and smoking. Soc Sci Res [Internet]. 2014;48:2034. Available from: http://dx.doi.org/10.1016/j.ssresearch.2014.05.007

10. Pennanen M, Haukkala A, De Vries H, Vartiainen E. Academic achievement and smoking: Is self-efficacy an important factor in understanding social inequalities in Finnish adolescents? Scand J Public Health [Internet]. 2011;39(7):714-22. Available from: http://journals.sagepub.com/doi/10.1177/1403494811420484

11. Latvala A, Rose RJ, Pulkkinen L, Dick DM, Korhonen T, Kaprio J. Drinking, smoking, and educational achievement: Cross-lagged associations from adolescence to adulthood. Drug Alcohol Depend. 2014;137(1):106-13.

12. Stiby Al, Hickman M, Munaf?? MR, Heron J, Yip VL, Macleod J. Adolescent cannabis and tobacco use and educational outcomes at age 16: birth cohort study. Addiction. 2015;110(4):658-68.

13. Stea TH, Torstveit MK. Association of lifestyle habits and academic achievement in Norwegian adolescents: a cross-sectional study. 2014;1-8.

14. Morin AJS, Rodriguez D, Fallu JS, Maïano C, Janosz M. Academic achievement and smoking initiation in adolescence: A general growth mixture analysis. Addiction. 2012;107(4):819-28.

15. Journal M, Konishi Y, Glewwe P. Does Smoking Make One Dumber? Evidence from Teenagers in Rural China. 2010 [cited 2018 Apr 23];37. Available from: http://repository.upenn.edu/gansu_papers

16. The Science of Addiction [Internet]. 2007 [cited 2018 Dec 28]. Available from: www.humanconnectomeproject.org

17. CDC. Tobacco Use and Academic Achievement. [cited 2018 Apr 16]; Available from: https://www.cdc.gov/healthyyouth/health_and_academics/pdf/tobacco_use.pdf

18. Cox RG, Zhang L, Johnson WD, Bender DR. Academic performance and substance use: findings from a state survey of public high school students. J Sch Health. 2007;77(3):109-15.

19. Atwoli L, Mungla PA, Ndung'u MN, Kinoti KC, Ogot EM. Prevalence of substance use among college students in Eldoret, western Kenya [Internet]. 2011 [cited 2018 Oct 16]. Available from: http://www.biomedcentral.com/1471-244X/11/34 
20. Pakistan National Human Development Report Summary Unleashing the Potential of a Young Pakistan [Internet]. [cited 2018 Dec 28]. Available from:

http://www.pk.undp.org/content/dam/pakistan/docs/HDR/NHDR_Summary 2017 Final.pdf

21. WHO global report on trends in prevalence of tobacco smoking 2015 [Internet]. 2015 [cited 2018 Dec 28]. Available from: www.who.int

22. Health CO on S and. Smoking and Tobacco Use; Fact Sheet; Health Effects of Cigarette Smoking. 2017 [cited 2017 Dec 14]; Available from:

https://www.cdc.gov/tobacco/data_statistics/fact_sheets/health_effects/effects_cig_smoking/index.htm

23. Drope J, Drope J, Schluger N, Cahn Z, Drope J, Hamill S, et al. TOBACCO ATLAS. [Internet]. 6th ed. Atlanta: MCGRAW-HILL EDUCATION; 2018 [cited 2018 Dec 28]. Available from: https://tobaccoatlas.org/topic/health-effects/

24. Rozi S, Butt ZA, Akhtar S. Correlates of cigarette smoking among male college students in Karachi, Pakistan. BMC Public Health [Internet]. 2007 Nov 1 [cited 2018 Apr 16];7:312. Available from: http://www.ncbi.nlm.nih.gov/pubmed/17976241

25. Khan FM, Husain SJ, Laeeq a, Awais a, Hussain SF, Khan J a. Smoking prevalence, knowledge and attitudes among medical students in Karachi, Pakistan. East Mediterr Heal J. 2005;11:952-8.

26. Noreen Shah1, Saad Siddiqui2. An overview of smoking practices in Pakistan. Pak J Med Sci [Internet]. 2015 [cited 2018 Dec 28];31(2):467-70. Available from: http://dx.doi.org/10.12669/pjms.312.6816

27. Current Cigarette Smoking Among Adults - United States, 2011 [Internet]. [cited 2019 Jan 1]. Available from: https://www.cdc.gov/mmwr/preview/mmwrhtml/mm6144a2.htm

28. BSc HOR., MSc MTA., S.2BSc H, BSc KS., BSc FMM., MSc RH., et al. Smoking Frequency and some Related Factors among High School Students of Kashan City, Iran. 2015; Available from:

file:///C:/Users/Khan/Downloads/kaums-iahs-v2n3p107-en (1).pdf

29. Sreeramareddy CT, Kishore P, Paudel J, Menezes RG. Prevalence and correlates of tobacco use amongst junior collegiates in twin cities of western Nepal: a cross-sectional, questionnaire-based survey. BMC Public Health [Internet]. 2008 Mar 26 [cited 2018 Apr 16];8:97. Available from: http://www.ncbi.nlm.nih.gov/pubmed/18366781

30. Eticha T, Kidane F. The Prevalence of and Factors Associated with Current Smoking among College of Health Sciences Students, Mekelle University in Northern Ethiopia. [cited 2019 Jan 1]; Available from: www.plosone.org

31. Nasir JA, Imran M, Chohan AA, Arif S, Zaidi A. IMPACT OF SOCIODEMOGRAPHIC FACTORS ON CIGARETTE SMOKING IN PAKISTANI MALES [Internet]. Vol. 7, KMUJ 2015. [cited 2018 Aug 17]. Available from: http://www.kmuj.kmu.edu.pk/article/viewFile/15148/pdf

32. Shah SM, Arif AA, Delclos GL, Khan AR, Khan A. Prevalence and correlates of smoking on the roof of the world [Internet]. [cited 2019 Jan 3]. Available from: www.tobaccocontrol.com

33. Yawar Alam A, Iqbal A, Bile Mohamud K, Laporte RE, Ahmed A, Nishtar S, et al. Investigating socioeconomic-demographic determinants of tobacco use in Rawalpindi, Pakistan. 2008 [cited 2018 Dec 28]; Available from: http://www.biomedcentral.com/1471-2458/8/50 
34. Hiscock R, Pearce J, Barnett R, Moon G, Daley V. Do smoking cessation programmes influence geographical inequalities in health? An evaluation of the impact of the PEGS programme in Christchurch, New Zealand. Tob Control [Internet]. 2009 Oct 1 [cited 2019 Jan 3];18(5):371-6. Available from: http://www.ncbi.nlm.nih.gov/pubmed/19556614

35. WHO. global adult tobacco survey pakistan. 2014 [cited 2018 Apr 23]; Available from: http://www.who.int/tobacco/surveillance/survey/gats/pak-report.pdf?ua=1

36. Hosseinpoor AR, Parker LA, Tursan D'espaignet E, Chatterji S. Social Determinants of Smoking in Low-and Middle-Income Countries: Results from the World Health Survey [Internet]. [cited 2018 Aug 16]. Available from: http://unstats.un.org/

37. Bian J, Du M, Liu Z, Fan Y, Eshita Y, Sun J. Prevalence of and factors associated with daily smoking among Inner Mongolia medical students in China: a cross-sectional questionnaire survey [Internet]. 2012 [cited 2018 Sep 19]. Available from: http://www.substanceabusepolicy.com/content/7/1/20

38. Bidstrup PE, Frederiksen K, Siersma V, Mortensen EL, Ross L, Vinther-Larsen M, et al. Social-cognitive and school factors in initiation of smoking among adolescents: a prospective cohort study. Cancer Epidemiol Biomarkers Prev [Internet]. 2009 Feb 1 [cited 2018 Apr 16];18(2):384-92. Available from: http://www.ncbi.nlm.nih.gov/pubmed/19190152

39. So ES, Park BM. Health Behaviors and Academic Performance Among Korean Adolescents. 2016 [cited 2018 Sep 4]; Available from: http://dx.doi.org/10.1016/j.anr.2016.01.004

\section{Figures}

\section{Age of Smoking Initiation among Students}

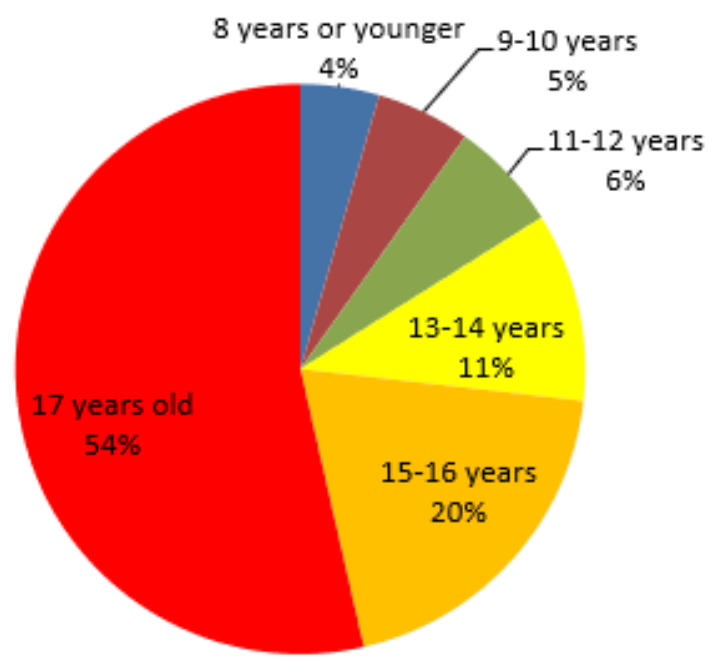

\section{Figure 1}

Age of Smoking Initiation Among Students 